\title{
Dairy Foods in a Moderate Energy Restricted Diet Do Not Enhance Central Fat, Weight, and Intra-Abdominal Adipose Tissue Losses nor Reduce Adipocyte Size or Inflammatory Markers in Overweight and Obese Adults: A Controlled Feeding Study
}

\author{
Marta D. Van Loan, ${ }^{1,2}$ Nancy L. Keim, ${ }^{1,2}$ Sean H. Adams, ${ }^{1,2}$ Elaine Souza, ${ }^{2}$ \\ Leslie R. Woodhouse, ${ }^{1}$ Anthony Thomas, ${ }^{2}$ Megan Witbracht, ${ }^{2}$ Erik R. Gertz, ${ }^{1}$ \\ Brian Piccolo, ${ }^{2}$ Andrew A. Bremer, ${ }^{3}$ and Michael Spurlock ${ }^{4}$ \\ ${ }^{1}$ Obesity \& Metabolism Research Unit, Western Human Nutrition Research Center, USDA, ARS, 430 West Health Science Drive, \\ Davis, CA 95616, USA \\ ${ }^{2}$ Department of Nutrition, University of California, Davis, CA 95616, USA \\ ${ }^{3}$ Pediatric Division, Vanderbilt Children's Hospital, Nashville, TN 37232-9170, USA \\ ${ }^{4}$ Department of Food Science and Human Nutrition, Iowa State University, Ames, IA 50011-1120, USA
}

Correspondence should be addressed to Marta D. Van Loan, marta.vanloan@ars.usda.gov

Received 6 April 2011; Revised 16 June 2011; Accepted 17 June 2011

Academic Editor: Jordi Salas Salvado

Copyright (C) 2011 Marta D. Van Loan et al. This is an open access article distributed under the Creative Commons Attribution License, which permits unrestricted use, distribution, and reproduction in any medium, provided the original work is properly cited.

\begin{abstract}
Background. Research on dairy foods to enhance weight and fat loss when incorporated into a modest weight loss diet has had mixed results. Objective. A 15-week controlled feeding study to determine if dairy foods enhance central fat and weight loss when incorporated in a modest energy restricted diet of overweight and obese adults. Design. A 3-week run-in to establish energy needs; a 12 -week $500 \mathrm{kcal} / \mathrm{d}$ energy reduction with 71 low-dairy-consuming overweight and obese adults randomly assigned to diets: $\leq 1$ serving dairy/d (low dairy, LD) or $\leq 4$ servings dairy/d (adequate dairy, AD). All foods were weighed and provided by the metabolic kitchen. Weight, fat, intra-abdominal adipose tissue (IAAT), subcutaneous adipose tissue (SAT) macrophage number, SAT inflammatory gene expression, and circulating cytokines were measured. Results. No diet differences were observed in weight, fat, or IAAT loss; nor SAT mRNA expression of inflammation, circulating cytokines, fasting lipids, glucose, or insulin. There was a significant increase $(P=0.02)$ in serum 25 -hydroxyvitamin $\mathrm{D}$ in the AD group. Conclusion. Whether increased dairy intake during weight loss results in greater weight and fat loss for individuals with metabolic syndrome deserves investigation. Assessment of appetite, hunger, and satiety with followup on weight regain should be considered.
\end{abstract}

\section{Introduction}

Obesity is a national epidemic with a multifaceted etiology and equally complex solutions. Epidemiological evidence has consistently shown the benefits of increased dairy intake on health, including an inverse relationship between dairy intake and body weight [1] and a lower incidence of insulin resistance with increasing dairy intakes [2]. Zemel et al. [3] first showed the relationship between dairy foods and body fat when conducting a clinical trial on the antihypertensive effects of calcium in obese African-Americans. Their findings showed that increasing dietary calcium from approximately $400 \mathrm{mg} / \mathrm{d}$ to $\sim 1,000 \mathrm{mg} / \mathrm{day}$, by the addition of yogurt to the diet, for one year resulted in a $4.9 \mathrm{~kg}$ reduction in body fat. Further work has suggested that dietary calcium with concomitant reductions in calcitriol could have antiinflammatory effects at the level of the macrophage and adipocyte. This body of work suggests that calcium-rich diets 
produce significant metabolic effects that result in reduced obesity risk and associated comorbidities.

Investigations that have examined the role of dairy products or calcium on weight and fat loss in human subjects have provided mixed results [4-7]. Drapeau and colleagues [4] examined changes in food patterns in the Québec Family Study, and reported increased consumption of fruits and skimmed milk were 2 food groups that were negatively related to increases in body weight over time. Major et al. [5] conducted a randomized, double-blinded placebo-controlled study to compare the effect of a 15-week weight loss program using calcium plus vitamin $\mathrm{D}$ supplementation versus placebo on fat loss. They found no statistically significant difference in fat loss for the calcium and vitaminD-supplemented group compared to the placebo group. But when the data were examined for just the very low calcium consumers $(<600 \mathrm{mg} / \mathrm{d})$, a significantly $(P<0.01)$ greater amount of weight and fat loss was observed in the $\mathrm{Ca}+\mathrm{D}$ group. However, there was also a corresponding reduction in fat intake, so the investigators concluded that the fat loss observed in the low calcium consumers was partially mediated by the reduction in dietary fat intake. Zemel and colleagues [6] conducted a 12-week weight loss study in which 2 of the 3 groups were instructed to consume a diet either low in dairy foods ( $\leq 1$ serving/d) or adequate in dairy foods (3 servings/d). The third group was given the low dairy diet plus calcium supplementation equivalent to the $\geq 3$ dairy foods/d group. All groups participated in a $500 \mathrm{kcal}$ energy restriction weight loss period for 12 weeks. Zemel et al. reported a significantly greater weight and fat loss in the adequate dairy group, an intermediate weight and fat loss in the calcium-supplemented group, and the least weight and fat loss in the low dairy group. Additional research by Zemel et al. [7] in a weight loss model examined changes in the distribution of body composition, based on DXA measurements, with either adequate calcium or adequate dairy intervention compared to low dairy diets and reported that the low dairy diet resulted in $5.3 \%$ loss of abdominal fat compared to losses of $12.9 \%$ and $14.0 \%$ for the adequate calcium and adequate dairy diets, respectively.

Contrary to the above findings, Holecki et al. [8] reported no significant differences in changes in body weight, body fat, parathyroid hormone, or $25-\mathrm{OH}$ vitamin $\mathrm{D}$ concentrations in 40 obese women who had been divided into 2 groups: diet with $\mathrm{Ca}+\mathrm{D}$ supplements versus diet only. Likewise HarveyBerino et al. [9] reported no significant difference between groups in weight or body fat losses after 12 months of a $500 \mathrm{kcal} / \mathrm{d}$ reduction in energy with either 1 serving of dairy foods/d or 3-4 servings of dairy foods/d incorporated into the diet plan. Thompson et al. [10] reported results from a randomized trial with three $-500 \mathrm{kcal} / \mathrm{d}$ restricted diets (control, low calcium, and high calcium) and found no significant differences in weight and fat loss between diet groups.

Several mechanisms of action have been proposed to explain the potential effects of high-calcium diets to reduce adiposity and inflammation. Higher intake of calcium may decrease the absorption of fat when calcium-fatty-acid soaps are formed, resulting in increased fecal fat excretion [11]. In addition, increased Ca intake can promote lipid oxidation [12] and/or blunt parathyroid hormone release [13]. Additionally, observations have been made that suggest that the modulation of adipocyte intracellular calcium $\left[\mathrm{Ca}^{2+}{ }_{i}\right]$ by the calcium-regulated hormone calcitriol may be important in regulating adipocyte function, with reductions in calcitriol following dietary calcium provision promoting lipid mobilization while reducing energy storage through changes in metabolic gene expression [3]. Notably, the work of Jones et al. [14] demonstrated an increase in $\left[\mathrm{Ca}^{2+}{ }_{\mathrm{i}}\right]$-promoted energy storage pathways in human adipocytes by stimulating expression and activity of fatty acid synthase and by inhibiting lipolysis.

Chronic inflammation of white adipose tissue (WAT), especially in visceral depots, contributes to the pathogenesis of obesity-related morbidities including insulin resistance and type 2 diabetes [14-16]. Macrophages infiltrate WAT with increasing adiposity and are a prominent cellular source of proinflammatory cytokine production [14]. Recent cell culture data from Sun and Zemel [15] indicated that calcitriol increased proinflammatory cytokine gene expression and protein secretion from adipocytes and macrophages, and this response was dependent on $\mathrm{Ca}^{2+}{ }_{\mathrm{i}}$-provoked reactive oxygen species (ROS) generation. Coculture of both cell types increased gene expression and protein secretion of proinflammatory cytokines, which was further enhanced by calcitriol [15]. In vivo evidence for the potential antiinflammatory properties of high dietary calcium both with and without dairy was demonstrated in the aP2-agouti transgenic mouse model of obesity, in which a high $\mathrm{Ca}$, nonfat dry milk protein-based diet reduced WAT inflammatory gene expression and circulating cytokines. Furthermore, weight loss has been shown to promote a reduction in plasma markers of inflammatory cytokines [16] and lower inflammatory marker gene expression in subcutaneous WAT, at least with very low-calorie diets.

Obesity is a multifaceted disease and difficult to study outside of a controlled environment. Previous results assessing the roles of dairy and calcium on weight loss have been reported from studies in which controlled conditions were not optimal since they were typically performed in a setting that required subjects to prepare their own food, which might have contributed to the variability in results. Therefore, we proposed to examine the impact of dairy on adiposity and metabolism under conditions of a controlled feeding study. We examined, under the "gold standard" of a controlled feeding trial, the effects of 3-4 servings/d of dairy foods during moderate energy restriction on central fat and weight loss, changes in intra-abdominal adipose tissue (IAAT), metabolic rate, substrate utilization, vitamin D status, adipocyte size and subcutaneous adipose tissue (SAT) inflammation markers, and inflammatory cytokines. Our primary hypotheses were as follows: the inclusion of adequate servings of dairy foods (3-4/d) in a modest energyrestricted diet would (1) significantly increase weight and body fat loss compared to a control diet, (2) result in greater fat loss from IAAT depots, (3) decrease adipocyte size and inflammation by reducing WAT macrophage infiltration, and (4) reduce systematic inflammatory markers. 


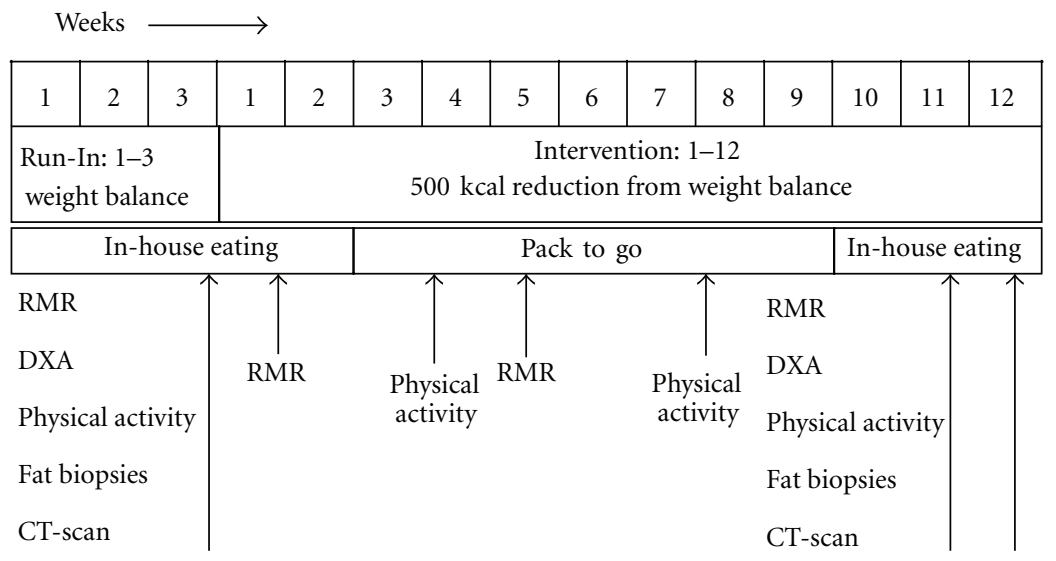

FIgure 1: Study design.

\section{Subjects and Methods}

2.1. Study Design. Healthy women, aged 20-45 years, and healthy men, aged $20-50$ years, were enrolled in a 15 -week controlled feeding study in which all foods were provided or prepared by the Metabolic Food Laboratory (MFL) at the USDA, ARS, Western Human Nutrition Research Center (WHNRC). The 15-week study was divided into a 3-week "run-in" period, during which subjects were weighed daily and caloric intake adjusted to maintain body weight, thereby establishing energy requirements. The "run-in" period was followed by a 12 -week energy reduction period $(-500 \mathrm{kcal} / \mathrm{d})$ (Figure 1). Energy intake for weight maintenance was initially calculated based on the DRI equation for overweight and obese adults [17]. Body weight was measured and recorded daily using an electronic scale. After a 5 day diet adjustment period, if weight increased or decreased for 3 consecutive days, caloric intake was adjusted (either up or down) until daily weight measurements were stable. During the last five days of the run-in period, subjects were assumed to be in energy balance, and this energy intake level was used to determine the reduced energy intake for the 12 -week intervention period.

2.2. Subject Screening and Selection. Overweight and obese adult females and males were recruited from the faculty, staff, and student populations at UC-Davis as well as the greater Davis and Sacramento communities. The lower cap on the age limit for women was used to avoid hormonal changes associated with the perimenopausal period that might affect endocrine parameters and related study outcomes. Body mass index was between 28 and $37 \mathrm{~kg} / \mathrm{m}^{2}$. Based on a dairy and calcium screening questionnaire, all participants were habitually low dairy consumers, defined as $\leq 1$ serving of dairy/d and a total calcium intake $\leq 600 \mathrm{mg} / \mathrm{d}$ from all sources including dairy. All were weight stable, defined as no more than $3 \mathrm{~kg}$ weight loss during three months preceding the intervention. Exclusion was based on not meeting the age and dairy serving criteria, diagnosis of type 2 diabetes requiring the use of any oral antidiabetic agent and/or insulin, fasting glucose $\geq 110 \mathrm{mg} / \mathrm{dL}$, adverse response to study foods (lactose intolerance, dairy intolerance, dairy allergy determined by self-report), history or presence of significant metabolic disease (i.e., endocrine, hepatic, or renal), use of blood pressure- or lipid-altering medications, resting blood pressure $\geq 160 / 100 \mathrm{mg} / \mathrm{Hg}$, total cholesterol $\geq 300 \mathrm{mg} / \mathrm{dL}$, triglyceride value $\geq 400 \mathrm{mg} / \mathrm{dL}$, or $\mathrm{LDL} \geq 160 \mathrm{mg} / \mathrm{dL}$, history of eating disorder, presence of active gastrointestinal disorders such as malabsorption syndromes, pregnancy or lactation, use of obesity pharmacotherapeutic agents within the last 12 weeks, use of over-the-counter antiobesity agents (e.g., those containing phenylpropanolamine, ephedrine, and/or caffeine) within the last 12 weeks, use of calcium supplements in the past 12 weeks, recent (past four weeks) initiation of an exercise program, recent (past 12 weeks) initiation of hormonal birth control or change in hormonal birth control regimen, use of tobacco products, and exercise more than 30 minutes/day.

2.3. Subject Randomization and Treatment. Body composition was assessed during the "run-in" period, and because body fatness could potentially affect the outcome, subjects were pair-matched based on percent body fat (\%BF) (to ensure an equal degree of body fatness in each treatment arm prior to the intervention) and randomly assigned to one of two treatment groups: low dairy (LD) ( $\leq 1$ serving/d) or adequate dairy (AD) (3-4 servings/d). Enrollment was continuous with a new cohort starting approximately every 8 weeks. Consequently, volunteers were enrolled year-round. Since this strategy could influence a subject's vitamin D status, the season at time of enrollment was coded in the database for use in the statistical analysis. The consort diagram (Figure 2) provides information on the number of eligible participants versus enrolled participants. Forty percent of the participants were nonwhite, and 25\% of those were of Hispanic origin.

2.4. Food Intake. The diets for the treatment arms were constructed to provide comparable levels of macronutrients and fiber and to approximate the average composition of caloric consumption in the US (fat $\sim 35 \%$ of total energy, carbohydrates $\sim 49 \%$, protein $\sim 16 \%$, and fiber $8-10 \mathrm{~g} / 1000 \mathrm{kcal})$. 




FIgURE 2: Consort diagram. Six individuals withdrew from the study prior to protocol completion and were excluded from data analysis.

Nutritional supplements were not permitted, and caffeine intake was maintained at a constant level (individualized for each patient, based on baseline assessment). All foods were provided by the MFL of the WHNRC for the duration of the study. Diets were prescribed and monitored as follows: during the 3-week "run-in" phase, subjects were fed at the WHNRC dining room and during that time they were familiarized with the diet and instructed on serving sizes and how to note discrepancies in study diaries; subjects were required to eat 2 of the 3 meals/d in the dining room. The third meal was packed to go. Typically, subjects reported to the WHNRC dining room for breakfast, lunch was packed to go, subjects returned to the WHNRC for dinner, and the evening snack was packed to go. All weekend meals were packed to go. The pattern of eating 2 of the 3 meals/d at the WHNRC was continued during the first two weeks of the energy restriction intervention. Thus, for the first 5 weeks of the study, most meals were consumed at the WHNRC. For weeks 3-9 of intervention, subjects were "free-living," but all food was weighed, measured, and provided by the MFL staff for each individual's specific caloric needs. During this freeliving period, to ensure freshness and maintain food safety standards, fresh produce and all prepared foods were "packed out" twice weekly (Tuesday and Friday) for each subject. Subjects were instructed by MFL staff on proper preparation for all foods consumed at home. All subjects were provided with preprinted food records corresponding to the foods to be consumed on each day during the "pack-out" period. Food records were reviewed when subjects returned to pick up the next food allotment. For the last 3 weeks of intervention (weeks 10-12), subjects returned to the WHNRC and once again ate 2 of 3 meals/d in the dining room. Based on a $2100 \mathrm{kcal}$ menu, the adequate dairy (AD) diet included 3-4 servings of milk, yogurt, and cheese per day and averaged $1339 \mathrm{mg} \mathrm{Ca} / \mathrm{d}$ from all sources. The low dairy (LD) diet had $\leq 1$ serving of dairy (e.g., milk, yogurt, or cheese) per day with an average calcium intake of $460 \mathrm{mg} / \mathrm{d}$ from all sources.
Subjects in the $\mathrm{AD}$ group utilized dairy products ranging from low- or reduced-fat to full-fat products; specifically 1 or $2 \%$ fat milk depending on caloric needs, low-fat yogurt, and full-fat cheese. Independent laboratory analysis (Covance Inc., Madison, Wis) of composites made from the 7 day menu at $1800 \mathrm{kcal}$ (the most often prescribed level during intervention) were done to confirm calcium content of the diet.

2.5. Compliance. Daily diet records were the basis for determining compliance. Preprinted diet records showing all menu items and amounts were given to each subject at each meal. In addition to the direct observation by the MFL staff during in-house eating, subjects checked $(\sqrt{ })$ each food item indicating it was eaten and recorded any deviations when they occurred. The diet record was returned to the study dietitian upon completion of the meal during the in-house eating phase and biweekly during the "pack-out" phase. Diet diaries during the initial feeding weeks allowed for the training of subjects on correct procedures for diet diaries. Records were evaluated and a priori determination of compliance was based on adherence to (1) diet treatment: either LD $(\leq 1$ serving/d) or $\mathrm{AD}$ (3-4 servings/d), (2) energy intake within $200 \mathrm{kcal}$ of energy prescription, and (3) for the AD group $95 \%$ consumption of the 294 total dairy servings during the 12 week intervention. Only subjects who met all compliance criteria for a given week were recorded as compliant for that week. Total study compliance was defined as meeting weekly compliance for 10 of the 12 weeks. Dairy food servings consisted of $8 \mathrm{oz}$. $(240 \mathrm{~mL})$ low-fat $(1 \%)$ or reduced-fat $(2 \%)$ fluid milk, $8 \mathrm{oz}$. $(240 \mathrm{~mL})$ low-fat yogurt, $2 \mathrm{oz}$. (56g) processed cheese or $1.5 \mathrm{oz}$. (42 g) natural cheese delivering 250$350 \mathrm{mg} \mathrm{Ca}$, and at least 6 grams of dairy protein per serving. During the course of the project, individual circumstances arose in which subjects were not able to attend meals at the WHNRC dining room. In these cases, food and meals were packed and sent home with instructions on preparation and completion of the diet record according to the study 
TABLE 1: Average nutrient distribution over a 7-day menu for adequate and low-dairy diets at 1800 kilocalorie intake.

\begin{tabular}{lcc}
\hline Nutrient & $\begin{array}{c}\text { Adequate dairy } \\
\text { Mean } \pm \text { SD }\end{array}$ & $\begin{array}{c}\text { Low dairy } \\
\text { Mean } \pm \text { SD }\end{array}$ \\
\hline Energy, kcal & $1800.3 \pm 6.1$ & $1813.9 \pm 52.6$ \\
Total fat, g (\% energy) & $71.5(35.7) \pm 1.3$ & $73.1(36.3) \pm 2.8$ \\
Carbohydrate, g & $223.0(49.5) \pm 4.9$ & $223.7(49.3) \pm 7.1$ \\
(\% energy) & $74.9(16.6) \pm 2.7$ & $73.9(16.3) \pm 4.7$ \\
Protein, g (\% energy) & $50.5(11.2) \pm 6.8$ & $46.2(10.2) \pm 6.1$ \\
Animal protein, g & $24.5(5.4) \pm 5.4$ & $27.7(6.1) \pm 5.6$ \\
Vegetable protein, g & $211.8 \pm 111.6$ & $217.0 \pm 118.9$ \\
(\% energy) & $22.6 \pm 4.8$ & $18.2 \pm 5.9$ \\
Cholesterol, mg & $26.8 \pm 4.6$ & $29.7 \pm 4.2$ \\
Saturated fat, g & $17.0 \pm 3.8$ & $19.4 \pm 3.7$ \\
Monounsaturated, g & $8.0 \pm 2.6$ & $3.2 \pm 3.5^{*}$ \\
Polyunsaturated, g & $1288.4 \pm 94.6$ & $434.6 \pm 56.6^{*}$ \\
Vitamin D (calciferol) $\mu \mathrm{g}$ & & \\
Calcium, mg & &
\end{tabular}

Values are mean \pm SD for a 7-day menu.

* Denotes significant difference, $P<0.001$.

guidelines. Instances of illness, family emergencies, and so forth, in which diet treatment was not maintained, were accounted for in the overall compliance established for the study (i.e., 10 out of 12 weeks). All the 71 subjects that completed the study met compliance criteria. Macronutrient intake for both the $\mathrm{AD}$ and $\mathrm{LD}$ diets are shown in Table 1.

2.6. Body Composition Measurements. Weight was measured on an electronic scale (Scale-tronic model 6002; Wheaton, Ill, USA) to the nearest $0.1 \mathrm{~kg}$ with subjects in light clothing, all jewelry removed, pockets emptied, and shoes removed. Height was measured using a wall-mounted stadiometer (Ayrton Stadiometer model S100; Prior Lake, Minn, USA). Subjects were instructed to stand erect with the head level and to inhale fully. Height was measured and recorded to the nearest $0.1 \mathrm{~cm}$. Body mass index was calculated as $\mathrm{kg} / \mathrm{m}^{2}$. Waist circumference was measured in the standing position against bare skin with the abdomen relaxed and the arms hanging at the sides. The smallest horizontal circumference midway between the lateral lower rib and the iliac crest and at the end of a normal exhalation was recorded to the nearest $0.1 \mathrm{~cm}$. The average of two readings was reported for weight, height, and waist circumference. Weight was measured weekly during the intervention phase of the study.

Total lean and fat masses and percent body fat were assessed using dual energy X-ray absorptiometry (DXA, GE Lunar, Prodigy Model) during the run-in period and at the end of the 12-week intervention. Daily calibration procedures were carried out per manufacturer instructions. To reduce the variance in the measurement data, all DXA scans were analyzed by a single operator.

2.7. Intra-Abdominal Adipose Tissue Measurements (IAAT). IAAT was measured using computed tomography (CT) transabdominal slices (Siemens Somaton 16 CT Scanner).
Measurements were made at the level of the L4-L5 intervertebral space following procedures developed by Clasey et al. [18]. Scan slices were $0.5 \mathrm{~cm}$ with the subject in a supine position and arms stretched above the head. Measurements were made with no angulation and using a lateral pilot scout scan to determine proper location. Adipose tissue area was assessed using an attenuation range from -190 to -30 Hounsfield units. IAAT includes the adipose tissue contained in a measurement boundary formed by the internal most aspect of the abdominal and oblique muscle walls and the posterior aspect of the vertebral body. IAAT measurements by CT were made during the run-in and at the end of the 12week intervention. All measurements were made following a 12-hr overnight fast.

2.8. Resting and Postprandial Metabolic Rate (RMR and $P P M R)$. Subjects reported to the WHNRC metabolic unit for the measurement of metabolic rate in the morning following a 12-hr overnight fast. Subjects were made comfortable in a hospital bed and were instructed to rest quietly in a reclined position for 15 minutes. An automated metabolic measuring cart (Truemax 2400 Metabolic Measurement System, Parvomedics, Salt Lake City, Utah, USA) was used to measure rates of $\mathrm{O}_{2}$ consumption $\left(\mathrm{VO}_{2}\right)$ and $\mathrm{CO}_{2}$ production $\left(\mathrm{VCO}_{2}\right)$. Gas analyzers were calibrated using a certified gas mixture of known $\mathrm{O}_{2}$ and $\mathrm{CO}_{2}$ concentrations, and the flowmeter was calibrated using a $3 \mathrm{~L}$ syringe. The metabolic cart was calibrated prior to the RMR measurement and recalibrated with a new tube and filter prior to the controlled lunch. Respiratory gases were collected while subjects were in a semireclined position and wore a facemask fitted securely covering the nose and mouth. The facemask was attached to tubing connected to the cart mixing chamber. Through the facemask, subjects inhaled room air, and all expired breath was trapped by the mask and directed to the cart mixing chamber for volume and gas analyses. For RMR, respiratory gas exchange measurements were made for 20-30 minutes. The minute by minute data for this session were evaluated using a mathematical algorithm to determine the subject steady-state RMR. Respiratory exchange ratio (RER), $\mathrm{VCO}_{2} / \mathrm{VO}_{2}$, was also determined from the steady-state RMR measurement. For postprandial metabolic rate (PPMR), respiratory gases were collected for 10 minutes every hour over $10 \mathrm{hrs}$. following the meal, minute by minute data for these sessions were also run through the mathematical algorithm to determine the subject steady state PPMR and the postprandial RER for that hour. Throughout the protocol, subjects remained in their hospital beds. They consumed a controlled breakfast served between 08:25-08:45, and a controlled lunch served between 12:35-13:00, representing 25\% and $30 \%$ of their daily intervention energy prescription, respectively. Data collection ended at 18:00, four hours after the lunch meal. This protocol was scheduled during the last week of the run-in period and the final week of intervention. Energy expenditure was calculated using the Weir equation [19] and converted to kcal/day:

$$
\begin{aligned}
\mathrm{kcal} / \mathrm{min}= & \left(3.941 \times \mathrm{VO}_{2}\right)+\left(1.106 \times \mathrm{VCO}_{2}\right) \\
& -(2.17 \times \text { urinary } \mathrm{N}) .
\end{aligned}
$$


Units for $\mathrm{VO}_{2}$ and $\mathrm{VCO}_{2}$ are in $\mathrm{L} / \mathrm{min}$. To estimate urinary nitrogen excretion, in $\mathrm{g} / \mathrm{min}$, a spot urine collection was made at the time of the RMR measurement, and a constant rate of protein catabolism was assumed, equivalent to the 24hr protein intake, as reported by Bingham [20].

2.9. Assessment of Physical Activity. Subjects were instructed to maintain their usual physical activity throughout the study. Physical activity was monitored using an Actical physical-activity-monitoring device (Philips Electronics, Bend, Ore, USA). The Actical is an omnidirectional accelerometer that provides an objective and quantifiable measure of physical activity. Digital integration data acquisition incorporates intensity of movement into the activity count for sedentary, light, moderate, and vigorous levels of activity. Subjects were instructed to wear the Actical during all waking hours, except for bathing or other activities that involved submersion in water, for the week (7 days). The Actical was attached to a belt and worn over the left hip. At the end of the week, subjects returned the Actical to the WHNRC Physiology Support Lab where the data were downloaded for confirmation of completeness in terms of the number of days of data collection, frequency, and intensity of activity sessions. A day was considered complete if the Actical contained at least 12 hours of data. If there were fewer than 5 weekdays and 2 weekend days of recorded data, the Actical was returned to the subject for additional days. Actical data were collected during the run-in and at weeks 4,8 , and 12 of intervention.

2.10. Subcutaneous Adipose Tissue (SAT) Biopsies. Subcutaneous adipose tissue biopsies were obtained at the UC Davis Medical Center Clinical and Translation Science Center at run-in and at the end of the 12-week intervention following a 12-hr overnight fast. The study physician or nurse practitioner sterilized the gluteal region with a betadine scrub followed by wiping with alcohol. A $2 \%$ lidocaine HCL solution was used to desensitize the area by injecting approximately $4-8 \mathrm{~mL}$ of lidocaine in a fan-shaped area of the gluteus. A 14-gauge, 1.5 inch needle was used on a $20 \mathrm{~mL}$ syringe and inserted at the site of lidocaine $\mathrm{HCl}$ injection. Fat was aspirated as suction was applied to the syringe and needle and repeatedly rotated until approximately $4-6 \mathrm{~mL}$ adipose tissue was obtained. Following biopsy, the area was treated again with Betadine and bandaged. Biopsies at run-in and at week 12 were collected from opposite side of the buttocks. Each sample was immediately rinsed in ice cold phosphate buffered saline (PBS) to remove blood and further processed in 1 of 2 ways: (1) rinsed in RNAlater solution (Ambion, Austin, TX) and placed in $\sim 25 \mathrm{~mL}$ RNAlater solution or (2) again rinsed in fresh ice cold PBS and 3 aliquots frozen in liquid nitrogen for later histological analyses. RNAlater treated samples were placed on ice for transport to the WHNRC where samples were gently rocked overnight in a $4^{\circ} \mathrm{C}$ refrigerator, stripped of RNAlater solution and stored at $-80^{\circ} \mathrm{C}$ until isolation of total RNA.

2.11. Total RNA Isolation and Gene Expression Analysis. Total RNA was isolated from SAT using the Ribopure Kit (Ambion,
Austin, TX) according to manufacturer's instructions. RNA abundance was quantified using a NanoDrop ND-1000 Spectrophotometer (NanoDrop Technologies, Wilmington, DE). cDNA was synthesized from total RNA for each sample using Superscript III First-Strand Synthesis System for RT-PCR (Invitrogen, Carlsbad, CA) according to manufacturer's instructions. Gene expression measured by quantitative real time PCR utilized gene-specific TaqMan primers and FAMMGB labeled probes (Assays-on-Demand, Applied Biosystems, Foster City, CA) analyzed in duplicate for each sample using an ABI 7900HT instrument. The amplification crossing threshold (Ct) for the endogenous control gene (hprt1; hypoxanthine guanine phosphoribosyl transferase 1) was determined for each sample to correct for template loading differences across all target genes $(\Delta \mathrm{Ct}=$ target gene $\mathrm{Ct}-$ control gene $\mathrm{Ct}$ ). The expression values (baseline and endpoint) were determined relative to average baseline expression (not individual subject baseline pre-intervention). Due to the high inter-subject variability, only samples for which a baseline and endpoint expression value was determined were used in the analysis (Low Dairy $=29$ and Adequate Dairy = 26).

2.12. SAT Macrophage Infiltration and Inflammatory Phenotype. Thawed samples were fixed in $10 \%$ neutral buffered formalin overnight prior to immunological analysis of macrophage number and adipocyte size in the Spurlock laboratory at Iowa State University. Briefly, samples were removed from fixative no later than $24 \mathrm{hr}$ after collection and embedded in paraffin. Paraffin-embedded samples were sectioned to $4 \mu \mathrm{m}$ thickness and mounted onto microscope slides. Slides were subjected to hematoxylin and eosin Y staining on an automatic stainer. Cover slips were applied with mounting medium and slides placed in a $5^{\circ} \mathrm{C}$ oven to dry overnight. Visualization of adipocyte number and size on the hematoxylin and eosin $\mathrm{Y}$ (H\&E) stained slides was performed with a Zeiss light microscope and processed with AxioVision 4.8 software. Counting and measurement of adipocytes was carried out at 20x magnification on a randomly selected field by a single investigator blinded to sample treatment group. The field of vision was subdivided into four randomly placed $71,765.96 \mu \mathrm{m}^{2}$ boxes, and all adipocytes that were in or partially within a box were counted. Only adipocytes completely inside the designated boxes were measured for area. The cell number and areas from the four designated counting areas were combined for an average value. Following microscopy, the cover slips were removed and samples deparaffinized and rehydrated by submersion in xylene for 5 minutes repeated twice, $100 \% \mathrm{EtOH}$ twice for 3 minutes each, $90 \% \mathrm{EtOH}$ twice for 3 minutes each, $70 \%$ EtOH twice for 3 minutes each, $\mathrm{H}_{2} \mathrm{O}$ for 3 minutes each, and tris-buffered saline (TBS) for 5 minutes each. Following rehydration, samples were proteolytically digested with $2 \%$ proteinase $\mathrm{K}$ in TBS for 10 minutes and placed in TBS for 5 minutes. Slides were removed from TBS and treated with peroxisidase block (Dako, Glostrup, Denmark) for 5 minutes and rinsed with distilled water before being placed in fresh TBS for 5 minutes. Samples were treated with primary antibody (mouse antihuman CD68, a panmacrophage marker) for 30 minutes 
at room temperature and placed back into TBS for 5 minutes. Samples were incubated with secondary antibody (HRP rabbit antimouse $\operatorname{IgG}$ ) for 30 minutes at room temperature and placed back into TBS for 5 minutes. DAB chromogen substrate (Dako, Glostrup, Denmark) was applied to slides for 15 minutes to obtain the appropriate stain darkness, and slides were then dipped into distilled water prior to counterstaining. Slides were counterstained in one quarter strength Harris hematoxylin for $1 \mathrm{~min}$, rinsed with doubledistilled $\mathrm{H}_{2} \mathrm{O}$, dipped briefly in differentiating solution (Sigma-Aldrich, St. Louis, Mo, USA) two times, rinsed with tap water, and placed in Scott's tap water substitute for 1 minute, $95 \% \mathrm{EtOH}$ for 30 seconds, then eosin Y solution for 1 minute. Following counterstaining, samples were dehydrated 1 minute in 95\% EtOH repeated twice, 2 minutes in 100\% EtOH repeated twice, then cleared in xylene for 2 minutes. Dehydrated samples were allowed to dry before remounting the cover slip. A randomly selected area of the sample was visualized with a Zeiss light microscope and processed as previously described except only the adipocyte number, and the total number of CD68-positive (brownstained) cells were counted. To calculate the \% CD68-positive macrophage cells, the number of adipocytes counted in the same field of vision as the CD68 cells were added to the positive cells to get the total number of cells, and the number of CD68-positive cells was divided by the total cell count.

2.13. Systemic Inflammatory and Adipokine Markers. Fasting levels of insulin, leptin, adiponectin, proinflammatory cytokines (IL- $1 \beta$, IL-6, IL- $8, \mathrm{TNF} \alpha, \mathrm{PAI}-1)$ and the acute phase C-reactive protein (CRP) were measured at the run-in period and at 12-week of intervention. Serum levels of highsensitivity CRP (hsCRP) were measured using a chemiluminescence analyzer and high-sensitivity CRP kit (Immulite, Siemens Diagnostics; Deerfield, Ill, USA). All other inflammatory markers were measured using multiplex technology using manufacturer's instructions (Millipore Corporation, Billerica, MA and BioPlex, Bio-Rad, Richmond, Va, USA).

2.14. Blood Samples. Sterile phlebotomy procedures were followed to draw two $5 \mathrm{~mL}$ serum separator tubes (SST) and one $3 \mathrm{~mL}$ EDTA tube of blood during subject screening. These samples were sent to the CLIA-certified clinical chemistry laboratory at the UC Davis Medical Center for routine analysis of complete clinical chemistry panel, lipid, liver, and thyroid assessment and complete blood count with differentials. Results were reviewed to ensure that values were within normal clinical ranges. Fasting blood was also drawn at run-in and week- 12 of intervention, and serum and plasma were stored at $-80^{\circ} \mathrm{C}$ until analyzed. Samples for glucose, lipids, and triglyceride analyses were sent to the UC Davis Medical Center for analysis.

Serum vitamin D (calciferol) metabolites (25-OH vitamin $\mathrm{D}$ and $\left.1,25(\mathrm{OH})_{2} \mathrm{D}\right)$ were analyzed using standard RIA procedures (DiaSorin, Stillwater, MN and Immunodiagnostics Systems [IDS], Fountain Hills, Az, USA). Samples were processed in accordance with manufacturer's instructions. 25-hydroxyvitamin D was assayed using an equilibrium RIA procedure based on an antibody with specificity for
25(OH)D. The sample, antibody, and tracer were incubated for 90 minutes at $20-25^{\circ} \mathrm{C}$. Phase separation was accomplished after 20 minute incubation at $20-25^{\circ} \mathrm{C}$ with a second antibody-precipitating complex. An NSB/addition buffer was added after this incubation prior to centrifugation to aid in reducing the nonspecific binding. 1,25-dihydroxyvitamin $\mathrm{D}$ was analyzed using an immunodiagnostics system (IDS) RIA assay that is a complete assay system for the purification of $1,25(\mathrm{OH})_{2} \mathrm{D}$ in samples by immunoextraction followed by quantitation by ${ }^{125}$ I RIA.

Intact parathyroid hormone was analyzed using an Immulite instrument and a solid phase two-site chemiluminescent enzyme-labeled immunometric assay (Siemens Diagnostics; Deerfield, Ill, USA).

\section{Statistical Power, Sample Size, and Analysis}

Sample size was determined by power calculations using data from a multicenter study that employed a dairy intervention during weight loss [6]. Power calculations for weight loss were based on treatment differences of $4.57 \mathrm{~kg}$. Fat loss calculations were based on a treatment difference of $2.47 \mathrm{~kg}$. Based on a standard deviation of $6.32 \mathrm{~kg}$ and an alpha level of 0.05 , a sample size of 35 per treatment group provided a power of $84.6 \%$. For fat loss, a sample size of 35 with a standard deviation of $2.65 \mathrm{~kg}$ and an alpha of 0.05 resulted in a power calculation of $97 \%$.

Data analysis included descriptive statistics for physical and clinical characteristics and various study-related hormones. Data were evaluated for normality and transformed as needed prior to statistical analysis. Associations among variables were evaluated using Pearson's correlations, and significant effects of time and treatment were determined by analysis of variance (ANOVA). All statistical analyses were performed using SAS version 9.2 (SAS Institute, Cary, NC, USA).

\section{Results}

Physical characteristics of the subjects at run-in are shown in Table 2. Body weight, fat, and BMI were within the bounds of overweight and obesity classifications. Fasting plasma or serum concentrations of glucose, triglycerides, and lipids as well as blood pressures were normal. The average value for serum $25(\mathrm{OH}) \mathrm{D}$ was below the recommended levels, $50 \mathrm{nmol} / \mathrm{L}$, at the run-in period and ranged from 10$80 \mathrm{nmol} / \mathrm{L}$, consistent with the expectation that subjects were recruited as low-dairy consumers. Values for PTH were within normal limits.

Results for the primary outcomes, for example, changes in body weight, body fat, and intra-abdominal adipose tissue are displayed in Table 3. Analysis of variance indicated a significant time effect but no treatment effect. In other words, both groups lost significant amounts of body weight, body fat, and intra-abdominal adipose tissue over time, but inclusion of dairy products into the energy-restricted diet did not result in greater weight, fat, or IAAT losses for the AD group. There was no significant loss in lean body mass in 
TABLe 2: Physical characteristics of subjects at run-in.

\begin{tabular}{lccc}
\hline Parameter $(N=71)$ & Mean $\pm \mathrm{SD}$ & Minimum & Maximum \\
\hline Age, yrs & $32.5 \pm 9.5$ & 19 & 50 \\
Height, cm & $167.9 \pm 8.7$ & 150.0 & 188.6 \\
Weight, $\mathrm{kg}$ & $91.1 \pm 11.1$ & 62.1 & 113.4 \\
Body fat, $\mathrm{kg}$ & $38.8 \pm 7.1$ & 18.9 & 54.0 \\
Body fat, \% & $43.1 \pm 6.9$ & 22.4 & 55.1 \\
Lean body mass, kg & $48.4 \pm 9.5$ & 34.0 & 71.5 \\
IAAT, cc & $92.4 \pm 23.5$ & 55.8 & 177.6 \\
Waist & $94.4 \pm 8.1$ & 76.0 & 114.6 \\
circumference, cm & & & \\
Total cholesterol, & $159.4 \pm 27.6$ & 99.0 & 221.0 \\
mg/dL & $36.7 \pm 11.5$ & 19.0 & 71.0 \\
HDL, mg/dL & $104.7 \pm 21.6$ & 53.0 & 145.0 \\
LDL, mg/dL & $89.4 \pm 40.5$ & 33.0 & 196.0 \\
Triglycerides, mg/dL & $83.0 \pm 8.6$ & 68.0 & 107.0 \\
Glucose, mg/dL & $111.2 \pm 9.2$ & 92.0 & 136.0 \\
SBP, mmHg & $66.5 \pm 8.5$ & 51.0 & 98.0 \\
DBP, mmHg & $45.7 \pm 18.1$ & 18.8 & 97.4 \\
PTH, pg/mol & $35.1 \pm 15.1$ & 10.1 & 80.4 \\
25(OH)D, nmol/L & 39.0 \\
\hline
\end{tabular}

Values are mean \pm SD. IAAT: intra-abdominal adipose tissue; HDL: highdensity lipoprotein; LDL: low-density lipoprotein; SBP: systolic blood pressure; DBP: diastolic blood pressure; PTH: parathyroid hormone.

TABLE 3: Change in weight, body fat, and intra-abdominal adipose tissue in adult women and men consuming low-dairy (LD) or adequate dairy $(\mathrm{AD})$ diets after a 12-week caloric restriction intervention.

\begin{tabular}{lccc}
\hline Treatment & $\Delta$ Weight, kg & $\Delta$ Body fat, kg & $\Delta$ IAAT, cc \\
\hline $\mathrm{AD}$ & $-6.3 \pm 2.9^{* *}$ & $-5.2 \pm 2.8^{* *}$ & $-8.5 \pm 6.6^{* *}$ \\
$\mathrm{LD}$ & $-6.0 \pm 3.1^{* *}$ & $-5.1 \pm 3.0^{* *}$ & $-8.9 \pm 8.5^{* *}$ \\
\hline
\end{tabular}

Values are mean \pm SD. IAAT: intra-abdominal adipose tissue.

${ }^{* *} P=0.01$. Significant time effect only, no significant differences were observed by treatment group.

either group during the intervention $(\mathrm{LD}=-0.6 \mathrm{~kg} ; \mathrm{AD}=$ $-0.83 \mathrm{~kg})$.

Although there was no significant treatment effect on body fat loss, changes at a cellular level may be observed before whole body changes can be seen; therefore, we examined adipocytes to determine if there was a treatment effect on adipocyte size and adipose tissue macrophage quantity. There was a trend $(P=0.065)$ toward smaller adipocyte size in the $\mathrm{AD}$ group with weight loss ( $\mathrm{LD}-238.6 \pm 375806$; $\left.\mathrm{AD}-1562.8 \pm 2558.8 \mu \mathrm{M}^{2}\right)$. The change in macrophage number relative to the total number of adipocytes did not change during the study. Changes in the relative transcript abundances for inflammatory (TNF- $\alpha$, IL-6, MCP-1) and metabolic (FAS and UCP2) genes in SAT were not different between treatment groups, and there were no time $\mathrm{x}$ treatment interactions; thus, all samples (LD and $\mathrm{AD} ; n=55$ ) were combined to determine if there was an effect of weight loss (time) (Table 4). Most transcript levels were not changed
TABLE 4: Relative transcript abundances of inflammatory and metabolic markers in subcutaneous adipose tissue before and after diet intervention for all subjects.

\begin{tabular}{lcc}
\hline Gene & Baseline & Endpoint \\
\hline TNF- $\alpha$ & $100.0 \pm 8.3$ & $97.1 \pm 7.3$ \\
IL-6 & $100.0 \pm 11.1$ & $150.9 \pm 23.1^{*}$ \\
MCP-1 & $100.0 \pm 10.5$ & $105.2 \pm 8.5$ \\
CD68 & $100.0 \pm 5.3$ & $116.5 \pm 8.2$ \\
CD11b & $100.0 \pm 10.0$ & $117.3 \pm 12.0$ \\
CD11c & $100.0 \pm 9.1$ & $105.4 \pm 8.5$ \\
CD11d & $100.0 \pm 6.2$ & $133.2 \pm 9.6^{* *}$ \\
IL-1 $\beta$ & $100.0 \pm 14.1$ & $114.8 \pm 11.7$ \\
IL-10 & $100.0 \pm 7.7$ & $118.4 \pm 8.1$ \\
IL-15 & $100.0 \pm 6.1$ & $103.4 \pm 6.0$ \\
FAS & $100.0 \pm 12.6$ & $114.9 \pm 14.4$ \\
UCP2 & $100.0 \pm 4.4$ & $110.3 \pm 6.1$ \\
\hline
\end{tabular}

Values are expressed as $\%$ of baseline average level (mean + SEM). ${ }^{*} P=0.05$ and ${ }^{* *} P<0.01$ compared to baseline, paired $t$-test. TNF: tumor necrosis factor; IL: interleukin; MCP: monocyte chemoattractant protein; FAS: fatty acid synthase; UCP: uncoupling protein. $n=55$.

TABLE 5: Vitamin D parameters before and after a 12-week intervention of low-dairy (LD) or adequate dairy $(\mathrm{AD})$ diets.

\begin{tabular}{lcc}
\hline & \multicolumn{2}{c}{ Adequate dairy } \\
& Run-in & Week 12 \\
\hline $25(\mathrm{OH}) \mathrm{D}, \mathrm{nmol} / \mathrm{L}$ & $30.8 \pm 12.4^{\mathrm{a}}$ & $35.1 \pm 12.8^{\mathrm{b}}$ \\
$1,25(\mathrm{OH})_{2} \mathrm{D}, \mathrm{pmol} / \mathrm{L}$ & $120.9 \pm 21.9$ & $107.4 \pm 32.1$ \\
\hline \multicolumn{2}{c}{ Low dairy } \\
$25(\mathrm{OH}) \mathrm{D}, \mathrm{nmol} / \mathrm{L}$ & $38.7 \pm 16.7^{\mathrm{b}}$ & $39.6 \pm 18.1^{\mathrm{bc}}$ \\
$1,25(\mathrm{OH})_{2} \mathrm{D}, \mathrm{pmol} / \mathrm{L}$ & $120.5 \pm 24.6$ & $116.3 \pm 31.5$ \\
\hline
\end{tabular}

Values are mean \pm standard deviation.

Different superscripts denote significant difference between treatment groups $(P=0.02)$ and over time $(P=0.0009)$.

during the course of the study, with modest but significant increases in CD11d and IL-6 mRNA levels observed.

A significant treatment effect $(P=0.02)$ was observed for serum vitamin $\mathrm{D}$ concentrations (Table 5). The $\mathrm{AD}$ group initially had significantly lower serum 25(OH)D values compared to the LD group at the run-in period (Table 5), but there was a significant increase $(P=0.0009)$ in the percent change in $25(\mathrm{OH}) \mathrm{D}$ in the $\mathrm{AD}$ group with approximately a $17 \%$ increase by the end of the 12 -week intervention. However, examination of the range of values $(12-78 \mathrm{nmol} / \mathrm{L})$ indicates that some participants continued to have insufficient levels of $25(\mathrm{OH}) \mathrm{D}$. At run-in, $86 \%$ of all subjects had serum values less than $50 \mathrm{nmol} / \mathrm{L}$ while at the 12 -week time point, $79 \%$ had values $<50 \mathrm{nmol} / \mathrm{L}$. As expected, there was a small, but significant relationship between serum 25(OH)D and parathyroid hormone $(r=$ $0.18 ; P=0.036)$. No significant changes were observed in $1,25(\mathrm{OH})_{2} \mathrm{D}$ by treatment group; however, there was a trend $(P=0.06)$ toward a significant increase in the percent change of $1,25(\mathrm{OH})_{2} \mathrm{D}$ in the $\mathrm{AD}$ group at the end of the 12-week intervention; $7.5 \%$ increase for the $\mathrm{AD}$ group compared to $\sim 1 \%$ decline in the LD group. 
TABLE 6: Energy expenditure and physical activity characteristics in adult women and men consuming adequate dairy (AD) or lowdairy (LD) diets for 12 weeks on a caloric-restricted diet.

\begin{tabular}{|c|c|c|c|c|}
\hline & \multicolumn{4}{|c|}{ Adequate dairy } \\
\hline & \multicolumn{2}{|c|}{ Run-in } & \multicolumn{2}{|c|}{ Week 12} \\
\hline $\begin{array}{l}\text { Respiratory exchange } \\
\text { ratio: fasting }\end{array}$ & 0.84 & \pm 0.05 & 0.84 & \pm 0.05 \\
\hline $\begin{array}{l}\text { Respiratory exchange } \\
\text { ratio: postprandial }\end{array}$ & 0.85 & \pm 0.03 & 0.85 & \pm 0.03 \\
\hline $\begin{array}{l}\text { Resting metabolic rate } \\
(\mathrm{RMR}), \mathrm{kcal} / \mathrm{d}\end{array}$ & 1750 & \pm 272 & 1685 & \pm 269 \\
\hline $\begin{array}{l}\text { Postprandial metabolic } \\
\text { rate (PPMR), kcal }\end{array}$ & $1995^{\mathrm{a}}$ & \pm 306 & $1894^{\mathrm{b}}$ & \pm 274 \\
\hline $\begin{array}{l}\text { Total activity } \\
\text { expenditure, } \mathrm{kcal} / \mathrm{d}\end{array}$ & 814 & \pm 354 & 719 & \pm 280 \\
\hline $\begin{array}{l}\text { Sedentary activity, } \\
\mathrm{min} / \mathrm{d}\end{array}$ & 1049.0 & \pm 102.9 & 1059.0 & \pm 92.5 \\
\hline Light activity, $\min / \mathrm{d}$ & 200.3 & \pm 53.8 & 206.7 & \pm 41.8 \\
\hline \multirow[t]{3}{*}{$\begin{array}{l}\text { Moderate activity, } \\
\mathrm{min} / \mathrm{d}\end{array}$} & 152.9 & \pm 59.6 & 148.3 & \pm 56.7 \\
\hline & \multicolumn{4}{|c|}{ Low dairy } \\
\hline & \multicolumn{2}{|c|}{ Run-in } & \multicolumn{2}{|c|}{ Week 12} \\
\hline $\begin{array}{l}\text { Respiratory exchange } \\
\text { ratio: fasting }\end{array}$ & 0.83 & \pm 0.04 & 0.84 & \pm 0.05 \\
\hline $\begin{array}{l}\text { Respiratory exchange } \\
\text { ratio: postprandial }\end{array}$ & 0.83 & \pm 0.03 & 0.83 & \pm 0.03 \\
\hline $\begin{array}{l}\text { Resting metabolic rate } \\
(\mathrm{RMR}), \mathrm{kcal} / \mathrm{d}\end{array}$ & 1709.0 & \pm 315.6 & 1638.0 & \pm 325.3 \\
\hline $\begin{array}{l}\text { Postprandial metabolic } \\
\text { rate (PPMR), kcal }\end{array}$ & $1921^{\mathrm{a}}$ & \pm 292 & $1856^{\mathrm{b}}$ & \pm 240 \\
\hline $\begin{array}{l}\text { Total activity } \\
\text { expenditure, } \mathrm{kcal} / \mathrm{d}\end{array}$ & 716 & \pm 328 & 654 & \pm 291 \\
\hline $\begin{array}{l}\text { Sedentary activity, } \\
\mathrm{min} / \mathrm{d}\end{array}$ & 1046.0 & \pm 121.3 & 1066.0 & \pm 116.1 \\
\hline Light activity, $\min / \mathrm{d}$ & 207.4 & \pm 57.3 & 207.5 & \pm 8.2 \\
\hline $\begin{array}{l}\text { Moderate activity, } \\
\mathrm{min} / \mathrm{d}\end{array}$ & 140.1 & \pm 68.1 & 136.1 & \pm 64.0 \\
\hline
\end{tabular}

Values are mean $\pm \mathrm{SD}$; different superscripts denote significant difference over time.

No significant dairy treatment differences were observed in the RER after an overnight fast. However, the average postprandial (PP) RER measured during the 10-h postprandial protocol was significantly higher in the $\mathrm{AD}$ group at run-in and after intervention $(P<0.03)$ (Table 6). After controlling for fat-free mass, RMR was not different over time or between treatment groups, whereas PPMR was significantly lower at week 12 for both the $\mathrm{AD}$ and LD groups $(P<0.001)$ and did not differ between groups (Table 6). No significant difference was observed between treatment groups for total activity energy expenditure over time, as measured by total activity counts from the Actical monitors. The energy expenditure for daily activities represented approximately $42-46 \%$ of RMR at baseline for the AD and LD groups, respectively. Values for total activity expenditure were similar at the end of the study, representing $\sim 40-43 \%$ of RMR.
TABLE 7: Total activity counts per day in women and men consuming adequate dairy $(\mathrm{AD})$ or low-dairy $(\mathrm{LD})$ diets for 12 weeks on a caloric-restricted diet.

\begin{tabular}{lccc}
\hline \multicolumn{4}{c}{ Adequate dairy } \\
Week 1 & Week 4 & Week 8 & Week 12 \\
\hline $207,846.7^{\mathrm{a}} \pm$ & $198,531.6^{\mathrm{a}} \pm$ & $175,796.1^{\mathrm{b}} \pm$ & $180,292.1^{\mathrm{c}} \pm$ \\
$123,696.7$ & $90,535.9$ & $99,638.0^{\circ}$ & $116,312.3$ \\
\hline \multicolumn{4}{c}{ Low dairy } \\
$163,390.3^{\mathrm{a}} \pm$ & $174,650.1^{\mathrm{a}} \pm$ & $159,193.9^{\mathrm{a}} \pm$ & $151,193.1^{\mathrm{a}} \pm$ \\
$90,640.4$ & $104,178.9$ & $84,882.5$ & $86,144.2$ \\
\hline
\end{tabular}

Values are mean $\pm \mathrm{SD}$; different superscripts denote significant differences between weeks within treatment groups. No differences were observed between groups in total activity counts.

When the activity data were examined based on the total activity counts, the $\mathrm{AD}$ group demonstrated a slight decline in activity from the run-in period to that observed at 8 and 12 weeks of intervention (Table 7). Although not statistically different from the total activity count for the LD group, the decline in activity for the $\mathrm{AD}$ group was approximately $13-15 \%$. Using all subjects, there was a significant positive association between the change in body weight and total energy expenditure from daily physical activity $(r=0.33$; $P=0.0095)$. Similar associations were observed between the change in body weight and the amount of time $(\mathrm{min} / \mathrm{d})$ spent in light and moderate activity $\left(R^{2}=0.145\right.$ and $R^{2}=0.147$, resp.). Approximately $14 \%$ of the variance in the change in body weight could be explained by the amount of time spent in light or moderate activity. Conversely, a significant negative association was observed between change in body weight and amount of time spent in sedentary activity $(r=$ $-0.38 ; P=0.0025)$. Similar relationships were observed between the change in body fat and time spent in light or moderate physical activity.

Fasting serum lipids showed no change for those consuming the AD diet; total cholesterol, LDL, and HDL cholesterol were not higher in the $\mathrm{AD}$ group compared to the LD group following intervention (Table 8). Similarly fasting glucose, insulin, or HOMA did not change between groups; however, fasting insulin changed over time with a decrease of about $12 \%$ associated with weight loss. Fasting levels of other metabolism-related hormones were also examined. No significant difference was observed between treatment groups or over time for leptin or adiponectin. Circulating levels for the proinflammatory cytokines Il- $1 \beta$, Il- 6 , Il- 8 , and TNF- $\alpha$, and hs-CRP did not change with treatment but did decline significantly over time associated with weight loss (Table 9).

\section{Discussion}

We demonstrated that the inclusion of 3-4 servings/d of dairy foods in a moderate energy-restricted diet for overweight and obese individuals, who were low-dairy consumers at initiation of the study, did not result in significantly greater amounts of central fat and weight loss compared to an energy-restricted diet with $\leq 1$ serving of dairy/d. Additionally, we did not observe greater IAAT loss for the subjects consuming the $\mathrm{AD}$ diet, nor a greater reduction in adipose 
TABLE 8: Serum lipids, glucose, and insulin parameters in women and men consuming adequate dairy (AD) or low-dairy (LD) diets for 12 weeks.

\begin{tabular}{|c|c|c|c|c|}
\hline \multirow[t]{2}{*}{ Parameter } & \multicolumn{2}{|c|}{ Adequate dairy } & \multicolumn{2}{|c|}{ Low dairy } \\
\hline & Run-in & Week 12 & Run-in & Week 12 \\
\hline Cholesterol, $\mathrm{mmol} / \mathrm{L}$ & $4.09 \pm 0.74$ & $4.08 \pm 0.81$ & $4.16 \pm 0.69$ & $4.12 \pm 0.81$ \\
\hline$(\mathrm{mg} / \mathrm{dL})$ & $(158.1 \pm 28.6)$ & $(157.8 \pm 31.1)$ & $(160.5 \pm 26.9)$ & $(159.2 \pm 31.3)$ \\
\hline $\mathrm{LDL}, \mathrm{mmol} / \mathrm{L}$ & $2.69 \pm 0.61$ & $2.97 \pm 0.61$ & $2.74+0.52$ & $2.74 \pm 0.68$ \\
\hline$(\mathrm{mg} / \mathrm{dL})$ & $(103.7 \pm 23.5)$ & $(102.9 \pm 23.7)$ & $(105.7 \pm 20.0)$ & $(105.8 \pm 26.4)$ \\
\hline $\mathrm{HDL}, \mathrm{mmol} / \mathrm{L}$ & $0.96 \pm 0.29$ & $0.93 \pm 0.30$ & $0.95 \pm 0.31$ & $0.92 \pm 0.28$ \\
\hline$(\mathrm{mg} / \mathrm{dL})$ & $(37.0 \pm 12.2)$ & $(36.1 \pm 11.6)$ & $(36.5 \pm 11.9)$ & $(35.6 \pm 10.9)$ \\
\hline Glucose, $\mathrm{mmol} / \mathrm{L}$ & $4.6 \pm 0.5$ & $4.8 \pm 0.5$ & $4.6 \pm 0.5$ & $4.7 \pm 0.4$ \\
\hline$(\mathrm{mg} / \mathrm{dL})$ & $(83.6 \pm 9.1)$ & $(86.3 \pm 8.8)$ & $(82.5 \pm 8.2)$ & $(84.9 \pm 7.1)$ \\
\hline Insulin, $\mathrm{pmol} / \mathrm{L}$ & $271.2 \pm 210.7$ & $229.7 \pm 151.1$ & $225.7 \pm 112.7$ & $205.7 \pm 101.4$ \\
\hline HOMA & $3.1 \pm 2.4$ & $2.7 \pm 1.8$ & $2.6 \pm 1.4$ & $2.4 \pm 1.2$ \\
\hline
\end{tabular}

Values are mean $\pm \mathrm{SD}$.

tissue gene expression of inflammatory markers or in circulating inflammatory cytokines. The findings of the present study are in agreement with results reported by some investigators $[5,8-10,21]$ but in contrast with other studies that demonstrated a greater reduction in fat mass with dairy intervention [6, 7, 11, 12, 22, 23]. Researchers in Australia [24] compared 3 servings of dairy foods per day to 5 servings/d, within the context of a reduced calorie diet, on changes in body weight and fat in overweight individuals during a 12week intervention. They reported significantly greater weight and fat loss in the group receiving 5 servings of dairy/d. Kadooka et al. [25] reported a significant decrease in abdominal visceral fat in obese adults who received fermented milk (e.g., yogurt with probiotics), and Faghih et al. [26] compared the effect of cow's milk, fortified soy milk, and calcium supplementation on weight and fat loss, reporting a significant treatment effect with the cow milk group having the greatest weight loss. Differences in outcomes across clinical studies with dairy and calcium interventions might be explained by the lack of control for individual differences in food self-selection during dietary intervention with different amounts of dairy and/or calcium (e.g., changes in intakes of fats or other calorie sources due to experimental interventions). However, by providing all the food for the present study and matching subjects on adiposity, our study allowed for a direct assessment of the effects of increasing dairy and calcium consumption on metabolic outcomes without confounding effects of other dietary changes that may occur in free-living research volunteers.

Another possibility for our discrepant results compared to prior studies may be the "dairy effect" requires a longer period of time to see an impact on weight gain and fat accumulation over time rather than an effect on weight and fat loss. Specific to this point is the research by Gunther et al. [21] and Eagan et al. [22]. Gunther and colleagues documented no benefit of dairy products to modulate body weight or fat mass in young free-living women over a 1-year intervention. However, a six month followup by Eagan et al. [22] with the same group of women found a significant effect of dietary calcium to reduce body fat accumulation. Research by Bush et al. [23] also found that dietary calcium
TABLE 9: Endocrine hormones and inflammatory cytokines in women and men consuming adequate-dairy (AD) or low-dairy (LD) diets following a 12 week intervention.

\begin{tabular}{lcccc}
\hline & \multicolumn{2}{c}{ Adequate dairy } & \multicolumn{2}{c}{ Low dairy } \\
& Run-in & Week 12 & Run-in & Week 12 \\
\hline $\begin{array}{l}\text { Leptin, } \\
\text { ng/mL }\end{array}$ & $39.5 \pm 23.7$ & $29.5 \pm 24.0$ & $28.7 \pm 21.0$ & $21.7 \pm 16.5$ \\
$\begin{array}{l}\text { Adiponectin, } \\
\text { ug/mL }\end{array}$ & $13.7 \pm 7.2$ & $13.8 \pm 6.7$ & $14.7 \pm 7.6$ & $15.2 \pm 7.1$ \\
PAI-1, Um/L & $19.2 \pm 16.3$ & $16.0 \pm 11.3$ & $21.5 \pm 15.6$ & $19.5 \pm 19.1$ \\
IL-1 $\beta, \mathrm{pg} / \mathrm{mL}$ & $0.56 \pm 1.12$ & $0.41 \pm 0.69$ & $0.48 \pm 0.47$ & $0.48 \pm 0.51$ \\
IL-6 pg/mL & $3.38 \pm 2.86$ & $3.20 \pm 2.72$ & $3.97 \pm 4.97$ & $3.30 \pm 3.96$ \\
IL-8, pg/mL & $1.58 \pm 1.10$ & $1.53 \pm 0.67$ & $1.51 \pm 0.85$ & $1.61 \pm 1.01$ \\
TNF- $\alpha$, & $3.15 \pm 1.65$ & $3.07 \pm 1.51$ & $3.07 \pm 1.63$ & $3.19 \pm 1.46$ \\
pg/mL & & & & \\
hs-CRP, mg/L & $3.4 \pm 4.5$ & $2.4 \pm 2.4$ & $2.5 \pm 3.3$ & $2.1 \pm 3.8$ \\
\hline
\end{tabular}

Values are mean $\pm \mathrm{SD}$.

IL: interleukin; TNF: tumor necrosis factor; hsCRP: high-sensitivity Creactive protein.

intake was significantly associated with less gain in IAAT over $1 \mathrm{yr}$. in premenopausal women. These studies suggest that any effect of dairy intake may be cumulative over a longer period of time, perhaps as part of a satiety/appetite regulation mechanism. More recently research, reported by Gilbert et al., [27] provided more evidence of an appetitesuppression effect of dairy foods. Specifically, in a 6 mo. milk supplementation single-blind placebo-controlled weight loss trial, there was a significant treatment by time interaction that resulted in a smaller increase in desire to eat and hunger, suggesting that incorporation of milk into a weight loss diet modulates the orexigenic effect of weight loss. The controlled feeding design of the present study, allowing for the control of all food intake, prevented us from being able to observe a similar influence of dairy foods on appetite and hunger and a voluntary reduction of food and energy intake. Regardless, an important point to make is that while increasing dairy consumption did not increase fat or weight loss, inclusion of dairy foods in a weight loss paradigm did not compromise weight loss. 
Furthermore, we did not see an adverse increase in serum lipids as a result of the AD diet which is in contrast to the findings of Wennersberg et al. [28]. The difference between our results and those of Wennersberg et al. can be explained by the difference in the dairy foods incorporated into our menu. We used 1 or $2 \%$ fat milk (depending on caloric needs), low-fat yogurt, and full-fat cheese with saturated, mono- and polyunsaturated fats balanced between the LD and $\mathrm{AD}$ menus. Wennersberg et al. used a higher fat diet and included more saturated fats, for example, cream $12-40 \%$ fat, cheese $15-30 \%$ fat, and butter or butter spreads $40-80 \%$ fat.

There have been mixed reports on the effect of calcium intake to promote fat substrate utilization $[4,5,29,30]$, which could be a potential mechanism by which increased calcium or dairy intake impacts weight and fat loss. Melanson et al. [31] examined 24-h energy expenditure, using a room calorimeter, in a group of healthy, young adult, nonobese men and women and reported that an acute intake of calcium was positively correlated with fat oxidation over 24 hrs, during sleep, and during light physical activity. Also, acute calcium intake was inversely related to 24 -h RER. Conversely, habitual calcium intake was not associated with increased fat oxidation. In contrast, Jacobsen and colleagues [11] reported that in young normal-weight adults under isocaloric conditions, short-term calcium intake, as high as $1800 \mathrm{mg} / \mathrm{d}$, had no effect on total energy expenditure or fat oxidation, but fecal fat excretion increased about 2.5-fold. Teegarden and coworkers [12] examined energy expenditure and fat oxidation in 24 young adult overweight women and found (after controlling for fat-free mass) that those taking $900 \mathrm{mg} / \mathrm{d}$ as calcium supplements had a significantly higher $(P=0.02)$ rate of fat oxidation after a test meal challenge $(1.5 \mathrm{~g} / \mathrm{hr})$ compared to the control group or those consuming $900 \mathrm{mg} / \mathrm{Ca}$ via dairy foods. Cumming et al. [29] reported significantly higher rates of fat oxidation in a group of middle-aged overweight and obese men and women following a high-calcium breakfast meal, either dairy or supplements, compared to the low-calcium breakfast. Although our subject characteristics were similar to those of Teegarden et al. and Cumming et al., we did not observe significant differences in the fasting RER, a measure of substrate utilization. However, we did observe that our AD group had a significantly higher postprandial RER compared to the LD group, but this difference was observed prior to initiation of the intervention diets, suggesting that there were inherent differences in substrate utilization between the groups.

The work of Zemel et al. [3], Shi et al. [30], and Sun and Zemel [32] in animal models and in vitro studies suggest that calcium and or dairy food may be a significant contributor to greater weight and fat loss. Sun and Zemel [32] demonstrated that high-calcium diets shift energy partitionin, thereby reducing weight gain during refeeding in obese mice. Based on the work of these investigators, vitamin D status (calcitriol, specifically) and its relationship to metabolic status are instrumental to the underlying hypothesis that the inclusion of dairy foods in a moderate energy-restricted diet will result in greater weight and fat loss. In our study, the overall values for serum vitamin $\mathrm{D}$ remained relatively stable in both groups (LD: 38.7 and $39.6 \mathrm{nmol} / \mathrm{L}$; AD: 30.8 and $35.1 \mathrm{nmol} / \mathrm{L}$ ), and serum calcitriol concentrations were not different between the LD and AD treatments (Table 5). Furthermore, the stability of the vitamin D levels explains the lack of a significant change in serum PTH. Therefore, we cannot discount the possibility that under our experimental conditions, the absence of dairy treatment effects on fat loss and inflammatory parameters may be explained in part by the lack of treatment-related changes in blood calcitriol levels. Although the AD diet provided greater dietary vitamin $\mathrm{D}$ intake, there was not a sufficient increase in circulating vitamin $\mathrm{D}$ to have a suppression effect. Furthermore, the observed increase in vitamin D was statistically significant; the absolute values was substantially lower than the recommended level. Our findings are in contrast to those reported by Cann et al. [33] from Women's Health Initiative (WHI) which demonstrated a small, but statistically significant effect of calcium and vitamin $\mathrm{D}$ to reduce weight gain over three years. Postmenopausal women with less than $1200 \mathrm{mg} / \mathrm{d} \mathrm{Ca}$ intake at baseline and randomized to supplements were 11\% less likely to experience small (1-3 kg) and modest (>3 kg) gains in weight. The exceptionally large sample size and the multiple years of followup for this study enabled the investigators to detect small changes in weight gain. Unfortunately, Cann and colleagues do not report serum levels for either $25-\mathrm{OH}$ vitamin $\mathrm{D}$ or $1,25(\mathrm{OH})_{2}$ vitamin $\mathrm{D}$ at baseline or for 3 -year followup that we might be able to compare results based on actual serum levels of vitamin D. Additionally, the WHI research volunteers were postmenopausal women with a different endocrine profile than our women who were premenopausal. A postmenopausal endocrine profile may be more responsive to the influence of high-calcium and vitamin $\mathrm{D}$ intakes than those in premenopausal women and adult men that were research volunteers in the present study.

The short duration and small sample size of the present study did not allow us to detect changes in body weight or body fat as small as $1 \mathrm{~kg}$ as observed in the WHI data. Additionally, a statistically significant finding for an outcome variable of weight gain over time is not the same as testing the outcome variable of weight loss and, therefore, cannot be directly compared.

Adipose tissue is an active endocrine organ that releases a number of metabolism-related hormones and cytokines into the circulation, and obesity is often marked by sub-clinical inflammation and WAT macrophage infiltration. However, research findings in this area [34-36] have reported conflicting results. We observed no changes in gluteal subcutaneous WAT inflammatory markers in our overweight and obese adults even with weight loss. Our subjects had low circulating levels of inflammatory markers at the start of the study, suggesting there was no underlying inflammation at the time of enrollment, and; therefore, no improvement could be detected with treatment. Furthermore, the hs-CRP values in our study subjects at the outset were on average within the AHA/CDC recommended normal range (1.0-3.1 mg/L) [36]. However, we did see small, but statistically significant improvements in leptin, CRP, and PAI-1 associated with weight loss.

Weight loss studies that focus on dietary interventions generally instruct the volunteers to maintain current 
physical activity levels; however, supporting data to confirm compliance with this request are generally lacking. In our study we demonstrated no change in daily physical activity level in the LD group over time and a small $(\sim 13-15 \%)$ decline in the AD group. However, due to the large variation in total activity counts (standard deviations of $\sim 90,000$ and 120,000 counts), there was no significant difference in activity between groups. Nonetheless, the $\sim 13-15 \%$ reduction in activity counting in the $\mathrm{AD}$ group during the latter half of the intervention may have resulted in somewhat less weight loss and fat loss as a result of a lower energy expenditure. To more thoroughly examine this possibility, we corrected energy expenditure for body weight and the change in body weight over the course of the intervention. When energy expenditure associated with daily physical activity was corrected for body weight, no differences were observed between the treatment groups. We also saw no significant change in lean body mass, and; thus, no change in the resting metabolic rate. Respiratory exchange ratio also did not change suggesting no change in substrate utilization between the groups. In summary, the fact that we observed no changes in lean mass, RMR, RER, and physical activity energy expenditure provide additional support for the concept that the change in body weight, body fat, and IAAT was due to caloric restriction and not other factors.

A limitation of our study was the power calculation and sample size determination. Although our calculations were based on previous research results, we may have been too ambitious in our expectation that we would observe more than a $4 \mathrm{~kg}$ difference in weight loss between the groups. In retrospect, a poststudy power analysis revealed a sample size of 112 subjects per group in order to detect a $1 \mathrm{~kg}$ difference in body weight $\pm 3 \mathrm{~kg}$ standard deviation with 80 percent power and an alpha level of 0.05 . Our inability to see treatment-related changes in endocrine and inflammatory parameters may also have been due to our strict inclusion criteria, particularly since healthy subjects without metabolic abnormalities may have had little room for improvement in their endocrine or inflammatory parameters. Additionally, the BMI range was limited to overweight and moderately obese individuals, thereby limiting comorbidities commonly seen with heavier individuals. Thus, inflammatory markers after weight loss may not similarly reflect those markers in body-weight- and adiposity-matched subjects that have not lost weight. Whether the inclusion of an adequate number of dairy servings in weight reduction diets of more obese individuals with metabolic disturbances improves metabolic and inflammatory parameters deserves further investigation.

In conclusion, the addition of 3-4 servings of dairy foods in a moderate energy-restricted diet of overweight and obese adult women and men did not result in greater weight and fat loss compared to the low-dairy diet. However, no adverse effects were seen on serum lipids with the inclusion of 3-4 servings of dairy foods, and increasing dairy and calcium intakes in the course of a calorie-restricted diet did not compromise fat or weight loss. Thus, given the importance of calcium and vitamin $\mathrm{D}$ to bone health, for weight loss diets that meet the US Dietary Guidelines for dairy foods, calcium and vitamin $\mathrm{D}$ are recommended. Whether increased dairy intake during weight loss results in greater weight and fat loss for individuals with metabolic syndrome deserves further investigation, but attention to study duration, controlled or free-living environment, and sufficient sample size will be critical for the detection of significant changes due to treatment. Consideration should also be given to assessment of appetite, hunger, and satiety with postintervention followup on weight regain.

\section{Conflict of Interests}

The authors have no conflict of interests to declare.

\section{Acknowledgments}

This study would not be possible without the efforts of a team of individuals starting with the research volunteers, the WHNRC metabolic food laboratory, human studies support, and physiology and analytical laboratory staff members. Additional support was provided by the UC-Davis Clinical and Translational Science Center nursing staff for assistance with blood draws and adipose biopsies. In addition, assistance was provided via the Radiology Department and technicians at the Northern California Veteran's Administration Mather Hospital for the intra-abdominal adipose tissue CT scans and analysis. Major funding for this project was provided by the National Dairy Council administered by the Dairy Research Institute and the Dairy Council of California. Additional support was provided by the USDA, ARS Projects 5306-51530-006-00D and 5306-51530-016-00D, the Clinical and Translational Science Center of the University of California, Davis, and grant no. UL1 RR024146 from the National Center for Research Resources (NCRR). The contents of this paper are the sole responsibility of the authors and do not represent the official view of NCRR, NIH, or USDA. M. D. Van Loan, N. L. Keim, S. H. Adams, E. Souza, L. R. Woodhouse were responsible for research design, study oversight, data analysis, and final preparation of the paper. A. Thomas, M. Witbracht, E. R. Gertz, and B. Piccolo were responsible for providing essential materials, specimen collection, data acquisition and analysis for respective areas of expertise, and corresponding contributions to the paper. A. A. Bremer was responsible for WAT biopsies, review of data analysis, and contribution to the final paper preparation. M. Spurlock was responsible for WAT macrophage analysis and data evaluation. This trial was registered at clinicaltrials.gov as NCT 00858312. USDA is an equal opportunity provider and employer.

\section{References}

[1] D. A. McCarron, C. D. Morris, H. J. Henry, and J. L. Stanton, "Blood pressure and nutrient intake in the United States," Science, vol. 224, no. 4656, pp. 1392-1398, 1984.

[2] M. A. Pereira, D. R. Jacobs, L. Van Horn, M. L. Slattery, A. I. Kartashov, and D. S. Ludwig, "Dairy consumption, obesity, and the insulin resistance syndrome in young adults: the CARDIA study," Journal of the American Medical Association, vol. 287, no. 16, pp. 2081-2089, 2002. 
[3] M. B. Zemel, H. Shi, B. Greer, D. Dirienzo, and P. C. Zemel, "Regulation of adiposity by dietary calcium," FASEB Journal, vol. 14, no. 9, pp. 1132-1138, 2000.

[4] V. Drapeau, J. P. Després, C. Bouchard et al., "Modifications in food-group consumption are related to long-term bodyweight changes," American Journal of Clinical Nutrition, vol. 80, no. 1, pp. 29-37, 2004.

[5] G. C. Major, F. P. Alarie, J. Dore, and A. Tremblay, "Calcium + vitamin D supplementation and fat mass loss in women very low calcium consumers: potential link with a calcium-specific appetite control," The British Journal of Nutrition, vol. 120, pp. 1538-1549, 2009.

[6] M. B. Zemel, D. Teegarden, M. Van Loan et al., "Dairy-rich diets augment fat loss on an energy-restricted diet: a multicenter trial," Nutrients, vol. 1, pp. 83-100, 2009.

[7] M. B. Zemel, W. Thompson, A. Milstead, K. Morris, and P. Campbell, "Calcium and dairy acceleration of weight and fat loss during energy restriction in obese adults," Obesity Research, vol. 12, no. 4, pp. 582-590, 2004.

[8] M. Holecki, B. Zahorska-Markiewicz, A. Wiecek, K. MiziaStec, T. Nieszporek, and A. Zak-Gołab, "Influence of calcium and vitamin D supplementation on weight and fat loss in obese women," Obesity Facts, vol. 1, no. 5, pp. 274-279, 2008.

[9] J. Harvey-Berino, B. C. Gold, R. Lauber, and A. Starinski, "The impact of calcium and dairy product consumption on weight loss," Obesity Research, vol. 13, no. 10, pp. 1720-1726, 2005.

[10] W. G. Thompson, N. R. Holdman, D. J. Janzow, J. M. Slezuk, K. L. Morris, and M. B. Zemel, "Effect of energy-reduced diets high in dairy products and fiber on weight loss in obese adults," Obesity Research, vol. 13, no. 8, pp. 1344-1353, 2005.

[11] R. Jacobsen, J. K. Lorenzen, S. Toubro, I. Krog-Mikkelsen, and A. Astrup, "Effect of short-term high dietary calcium intake on 24-h energy expenditure, fat oxidation, and fecal fat excretion," International Journal of Obesity, vol. 29, no. 3, pp. 292-301, 2005.

[12] D. Teegarden, K. M. White, R. M. Lyle et al., "Calcium and dairy product modulation of lipid utilization and energy expenditure," Obesity, vol. 16, no. 7, pp. 1566-1572, 2008.

[13] C. W. Gunther, R. M. Lyle, P. A. Legowski et al., "Fat oxidation and its relation to serum parathyroid hormone in young women enrolled in a 1-y dairy calcium intervention," American Journal of Clinical Nutrition, vol. 82, no. 6, pp. 12281234, 2005.

[14] B. H. Jones, J. H. Kim, M. B. Zemel et al., "Upregulation of adipocyte metabolism by agouti protein: possible paracrine actions in yellow mouse obesity," American Journal of Physiology, vol. 270, no. 1, pp. E192-E196, 1996.

[15] X. Sun and M. B. Zemel, "Role of uncoupling protein 2 (UCP2) expression and $1 \alpha, 25$-dihydroxyvitamin D3 in modulating adipocyte apoptosis," FASEB Journal, vol. 18, no. 12, pp. 1430-1432, 2004.

[16] L. M. Browning, J. D. Krebs, E. C. Magee, G. Frühbeck, and S. A. Jebb, "Circulating markers of inflammation and their link to indices of adiposity," Obesity Facts, vol. 1, no. 5, pp. 259$265,2008$.

[17] Institute of Medicine of the National Academies, Dietary Reference Intakes for Energy, Carbohydrate, Fiber, Fat, Fatty Acids, Cholesterol, Protein, and Amino Acids, The National Academies Press, Washington, DC, USA, 2005.

[18] J. L. Clasey, C. Bouchard, C. D. Teates et al., "The use of anthropometric and dual-energy X-ray absorptiometry (DXA) measures to estimate total abdominal and abdominal visceral fat in men and women," Obesity Research, vol. 7, no. 3, pp. 256-264, 1999.
[19] J. B. WEIR, "New methods for calculating metabolic rate with special reference to protein metabolism," The Journal of Physiology, vol. 109, no. 1-2, pp. 1-9, 1949.

[20] S. A. Bingham, "Urine nitrogen as a biomarker for the validation of dietary protein intake," Journal of Nutrition, vol. 133, supplement 3, pp. 921S-924S, 2003.

[21] C. W. Gunther, P. A. Legowski, R. M. Lyle et al., "Dairy products do not lead to alterations in body weight or fat mass in young women in a 1-y intervention," American Journal of Clinical Nutrition, vol. 81, no. 4, pp. 751-756, 2005.

[22] M. S. Eagan, R. M. Lyle, C. W. Gunther, M. Peacock, and D. Teegarden, "Effect of 1-year dairy product intervention on fat mass in young women: 6-Month follow-up," Obesity, vol. 14, no. 12, pp. 2242-2248, 2006.

[23] N. C. Bush, J. A. Alvarez, S. S. Choquette et al., "Dietary calcium intake is associated with less gain in intra-abdominal adipose tissue over 1 year," Obesity, vol. 18, no. 11, pp. 21012104, 2010.

[24] W. C. S. Ping Delfos, Higher dairy intake can help fight obesity, Ph.D. thesis, New Curtin University of Technology, Curtin, Australia, 2009.

[25] Y. Kadooka, M. Sato, K. Imaizumi et al., "Regulation of abdominal adiposity by probiotics (Lactobacillus gasseri SBT2055) in adults with obese tendencies in a randomized controlled trial," European Journal of Clinical Nutrition, vol. 64, no. 6, pp. 636-643, 2010.

[26] S. H. Faghih, A. R. Abadi, M. Hedayati, and S. M. Kimiagar, "Comparison of the effects of cows' milk, fortified soy milk, and calcium supplement on weight and fat loss in premenopausal overweight and obese women," Nutrition, Metabolism \& Cardiovascular Diseases, vol. 21, no. 7, pp. 499-503, 2011.

[27] J.-A. Gilbert, D. R. Joanisse, J.-P. Chaput et al., "Milk supplementation facilitates appetite control in obese women during weight loss: a randomised, single-blind, placebo-controlled trial," British Journal of Nutrition, vol. 105, no. 1, pp. 133-143, 2011.

[28] M. H. Wennersberg, A. Smedman, A. M. Turpeinen et al., "Dairy products and metabolic effects in overweight men and women: results from a 6-mo intervention study," American Journal of Clinical Nutrition, vol. 90, no. 4, pp. 960-968, 2009.

[29] N. K. Cumming, A. P. James, and M. J. Soares, "The acute effects of different sources of dietary calcium on postprandial energy metabolism," British Journal of Nutrition, vol. 96, no. 1, pp. 138-144, 2006.

[30] H. Shi, A. W. Norman, W. H. Okamura, A. Sen, and M. B. Zemel, "1alpha,25-dihydroxyvitamin D3 inhibits uncoupling protein 2 expression in human adipocytes," The FASEB Journal, vol. 16, no. 13, pp. 1808-1810, 2002.

[31] E. L. Melanson, T. A. Sharp, J. Schneider, W. T. Donahoo, G. K. Grunwald, and J. O. Hill, "Relation between calcium intake and fat oxidation in adult humans," International Journal of Obesity, vol. 27, no. 2, pp. 196-203, 2003.

[32] X. Sun and M. B. Zemel, "Calcium and dairy products inhibit weight and fat regain during ad libitum consumption following energy restriction in aP2-agouti transgenic mice," Journal of Nutrition, vol. 134, no. 11, pp. 3054-3060, 2004.

[33] B. Caan, M. Neuhouser, A. Aragaki et al., "Calcium plus vitamin D supplementation and the risk of postmenopausal weight gain," Archives of Internal Medicine, vol. 167, no. 9, pp. 893-902, 2007.

[34] M. B. Zemel, X. Sun, T. Sobhani, and B. Wilson, "Effects of dairy compared with soy on oxidative and inflammatory stress in overweight and obese subjects," American Journal of Clinical Nutrition, vol. 91, no. 1, pp. 16-22, 2010. 
[35] D. B. Panagiotakos, C. H. Pitsavos, A. D. Zampelas, C. A. Chrysohoou, and C. I. Stefanadis, "Dairy products consumption is associated with decreased levels of inflammatory markers related to cardiovascular disease in apparently healthy adults: the ATTICA study," Journal of the American College of Nutrition, vol. 29, no. 4, pp. 357-364, 2010.

[36] S. Pal and V. Ellis, "The chronic effects of whey proteins on blood pressure, vascular function, and inflammatory markers in overweight individuals," Obesity, vol. 18, no. 7, pp. 1354$1359,2010$. 


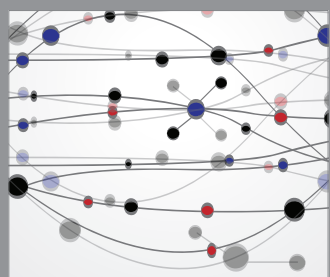

The Scientific World Journal
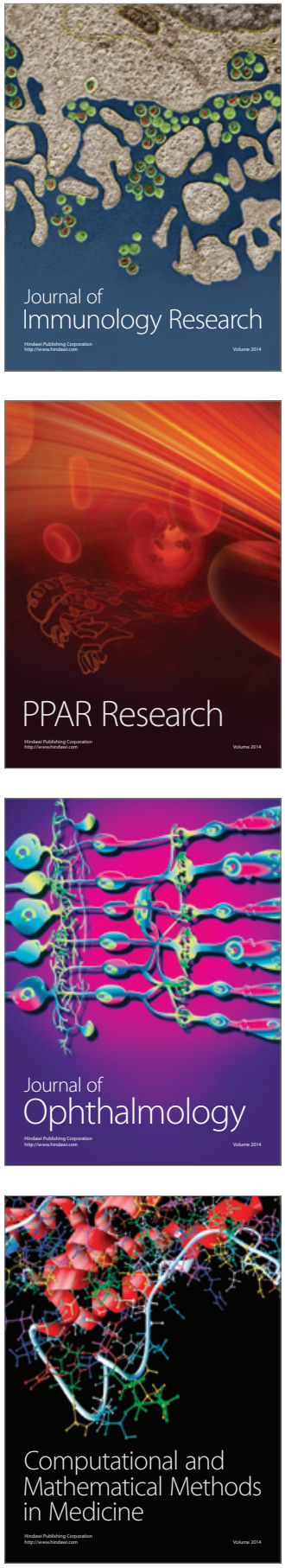

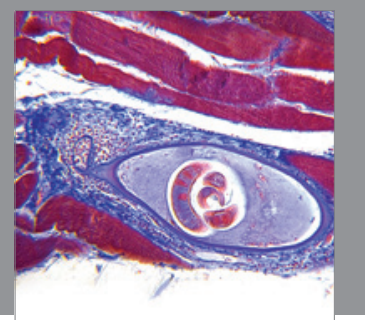

Gastroenterology

Research and Practice
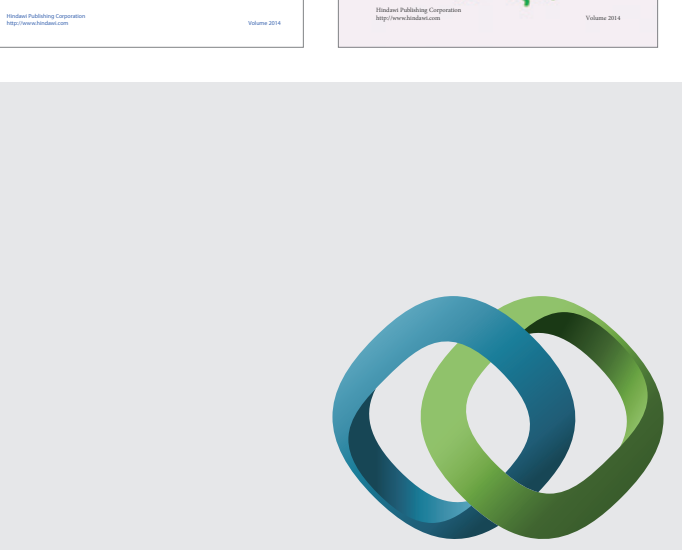

\section{Hindawi}

Submit your manuscripts at

http://www.hindawi.com
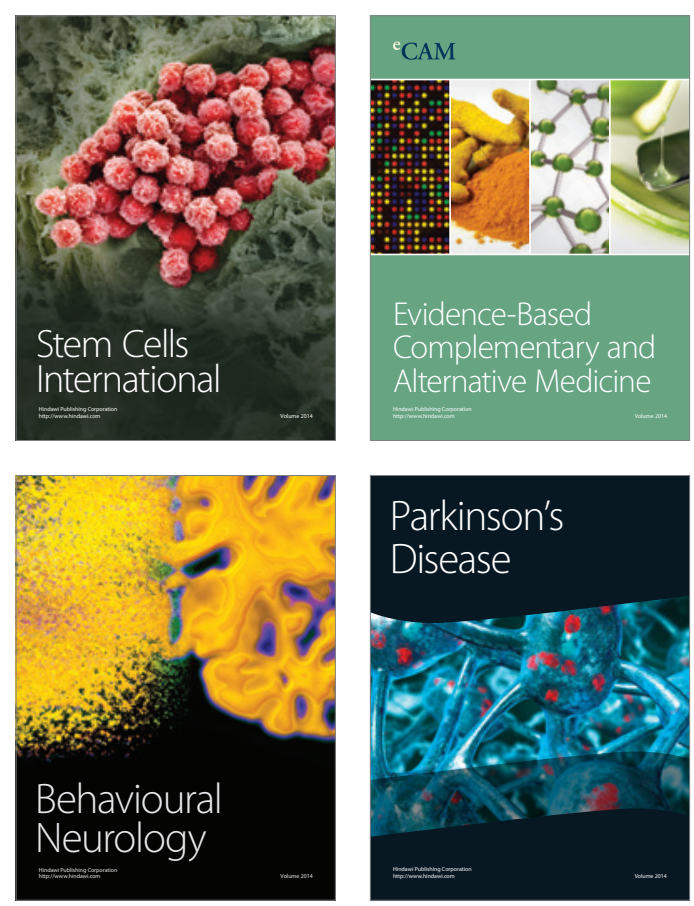

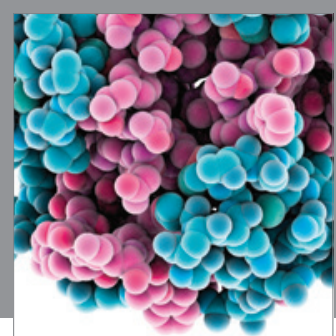

Journal of
Diabetes Research

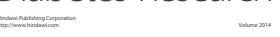

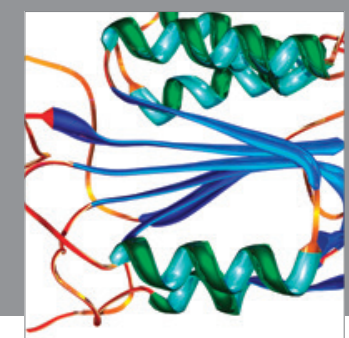

Disease Markers
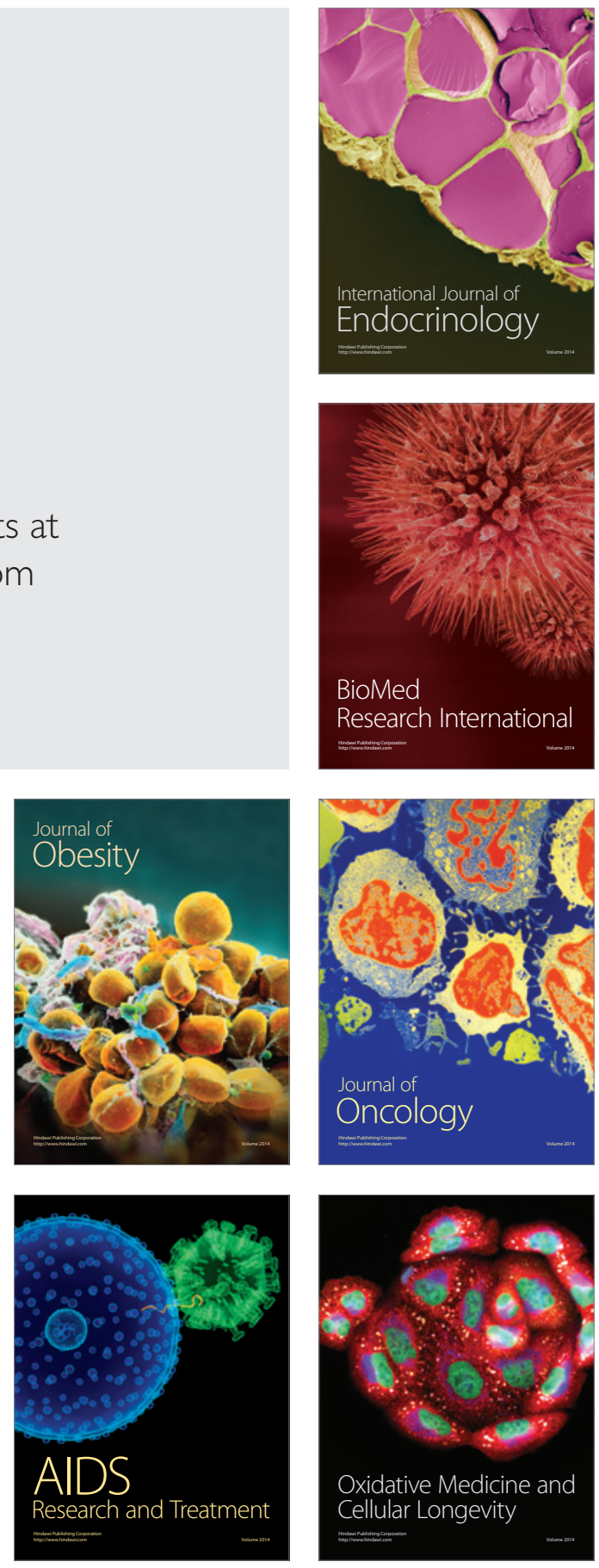